\title{
POLÍTICAS PÚBLICAS DE EDUCAÇÃO NO PARANÁ: CONTRATAÇÃO E CONDIÇÕES DE TRABALHO DE PROFESSORES TEMPORÁRIOS COMO VARIÁVEL DE ANÁLISE ${ }^{1}$
}

\author{
Marcelo Nogueira de Souza ${ }^{2}$
}

- Enviado em 23/01/2016

- Aprovado em 21/02/2016

A tese analisa, comparativamente, como vem sendo feito o processo de valorização da carreira dos professores estaduais da rede pública de ensino do Paraná, a maior categoria de funcionários públicos do estado, em dois períodos distintos: os últimos quatro anos do governo de Roberto Requião de Mello e Silva, do PMDB, assim como, também, os primeiros quatro anos do governo de Carlos Alberto Richa, do PSDB. Como se procurou demonstrar ao longo da tese, tratase de governos com perfis distintos, nos quais a execução das políticas refletiu a forma como os dois governos concebiam o papel do Estado naquele contexto.

Considerando a valorização da carreira docente como uma política pública de Estado e, apesar da sua concretização envolver muitos fatores - como formação inicial e continuada, condições de trabalho, remuneração e carreira, entre outras - utilizaremos como variável principal de análise, a contratação de professores temporários (PSS), prática recorrente nos dois governos aqui analisados.

Ao partirmos do princípio que o Estado - ente abstrato cujas ações se efetivam através de seus servidores - é necessário para a maioria da população, e que suas ações se dão, principalmente,

\footnotetext{
${ }^{1}$ Pesquisa de doutorado em andamento sob a orientação da Professora Doutora Maria Tarcisa da Silva Bega no Programa de Pós-graduação em Sociologia da UFPR.

${ }^{2}$ Mestre em Políticas Educacionais pelo Programa de Pós-graduação em Educação - UFPR. Endereço eletrônico: 666noma@gmail.com
} 
através dos serviços públicos prestados; sejam eles da área da saúde, educação, saneamento, segurança, etc, é fundamental que esses serviços sejam prestados com qualidade, a qual está diretamente relacionada a valorização de seus servidores.

O recorte temporal da pesquisa, que engloba o último mandato do governador Requião (2007-2010), assim como o primeiro mandato do governador Beto Richa (2011 - 2014), visou compreender os impactos dessa transição de governo para os professores do estado, através da análise das variáveis que compõem suas condições de trabalho. Condições estas que são consideradas fundamentais para uma concreta e efetiva valorização dos professores mas que, por configurarem o maior peso no cálculo do custo-aluno, têm sido alvo de controvérsias, resistências e até mesmo de conflitos, por parte das diferentes esferas governamentais.

A análise empreendida revela que, apesar de muitos direitos dos professores efetivos (QPM) terem sido estendidos aos professores temporários (PSS), estes ainda se encontram num quadro de precariedade - a qual buscamos compreender através dos conceitos de precariedade objetiva e subjetiva - que, para além de questões relativas à valorização do trabalho docente no estado, compromete a qualidade do ensino.

\section{METODOLOGIA}

A pesquisa segue os moldes de uma análise conjuntural. A análise conjuntural de políticas públicas e, mais especificamente, a análise que o presente trabalho pretende desenvolver, deve levar em conta o agravante de que estamos trabalhando com um Estado onde coexistem comportamentos político-administrativos modernos e tradicionais, o que torna necessária uma adaptação do conjunto de instrumentos da análise a essas condições peculiares, típicas de sociedades "em desenvolvimento" como a nossa. Nesse sentido, o presente estudo também se utilizará de alguns conceitos básicos da análise de políticas públicas, com destaque para as abordagens do neoinstitucionalismo e da análise de estilos políticos.

Associado ao neo-institucionalismo, a análise também privilegiará a análise de estilos políticos. Esta vertente da policy analysis é importante pelo destaque que dá aos aspectos culturais, aos padrões e atitudes, tanto de comportamentos políticos, como de atitudes de atores políticos 
singulares e essenciais para uma melhor compreensão do nosso processo político, uma vez que frisa fatores que repercutem na qualidade dos programas e projetos políticos elaborados e implementados.

Apesar da divergência de seus pressupostos básicos, a análise de estilos políticos e do neoinstitucionalismo (quando se leva em consideração o conceito ampliado de instituição) revela pontos de entrecruzamento dos seus respectivos objetos de investigação, uma vez que:

Ao examinar os padrões de comportamento político, a análise de estilos políticos tem que levar em consideração não apenas hábitos, costumes, rituais, estilos de comportamento e padrões de rotina política, mas também formas institucionalizadas de comportamento político (FREY, 2000, p. 241).

Ainda dentro da abordagem neo-institucionalista, também serão utilizados elementos da "análise de redes sociais", cujos estudos existentes, de acordo com Marques (2006, p.1), "têm explorado de forma inovadora as dinâmicas internas ao Estado e as suas relações com outros atores sociais, demonstrando a importância para a política do "tecido do Estado" - a sua estrutura relacional interna.

De acordo com o autor, apesar de se tratar de um campo de estudo recente, os poucos estudos existentes:

[...] têm permitido explorar de forma analiticamente inovadora certos fenômenos, em especial as dinâmicas internas ao Estado e as relações entre esse último e a sociedade mais ampla, no interior de comunidades de política pública específicas. Os resultados encontrados sugerem que os padrões de relação estruturados pelas redes influenciam os resultados da dinâmica política, assim como das políticas públicas (MARQUES, 2006, p.5).

Considerando que o objeto de estudo da presente tese são os professores temporários (PSS) da rede estadual pública do Paraná e que sua análise será feita com base no número de professores contratados temporariamente - através de uma análise comparativa das gestões dos governadores Roberto Requião (PMDB), de 2007 a 2010, e Carlos Alberto Richa (PSDB), de 2011 a 2014 assim como nas condições de trabalho e de remuneração dos mesmos, é importante explicitar, também, que a análise será feita através de análise documental. Tal escolha se justifica, na medida em que, ao contrário do setor privado, o funcionalismo público é regido por leis que estabelecem princípios aos quais o servidor é obrigado a seguir, ou seja: é a administração pública que, através de lei, específica, cria o cargo e determina a sua remuneração. As transformações na estrutura do 
Estado têm, como uma de suas consequências direta, a mudança na legislação, na interpretação e na aplicação das regras. De acordo com May (2004):

\begin{abstract}
afastando-se da idéia de que um documento independentemente relata a realidade social, ou que a sua produção é ainda outro método, pelo qual as pessoas constroem a ordem social, agora utilizamos os nossos próprios entendimentos culturais para "engajar-nos" com "significados" que estão embutidos no próprio documento. Então, os pesquisadores não se desculpam por serem parte do mundo social que estudam, mas pelo contrário, utilizam esse fato (MAY, 2004, p.113).
\end{abstract}

Neste sentido, a análise das fontes documentais visa compreender o contexto políticoinstitucional do período - os últimos quatro anos do mandato do governador Roberto Requião (2007 - 2010), assim como os quatro primeiros anos do mandato do governador Beto Richa (2011 2014) - governos que definiram diferentes estratégias políticas, orientadas por distintas concepções de Estado, sociedade e educação, que resultaram no estabelecimento de políticas públicas também diferenciadas.

\title{
RESULTADOS PARCIAIS
}

Através de uma comparação entre os direitos previstos na Lei Complementar 103/2004 (relativa aos professores efetivos do Estado) e na Lei Complementar 108/2005 (relativa aos professores temporários) e também nas mais recentes leis e decretos implementados, a análise empreendida revela que, apesar de muitos direitos dos professores efetivos (QPM) terem sido estendidos aos professores temporários (PSS), estes ainda se encontram num quadro de precariedade. A ausência de vínculo com o Estado os priva, ainda, de muitos direitos, apesar de compartilhar com os professores efetivos, os mesmos deveres. Esta diferenciação caracterizaria um tipo de precariedade intitulada como precariedade objetiva, que, de acordo com Casaca (2005), estaria relacionada à precariedade de direito, relacionando-se com os aspectos formais e jurídicos que contornam a relação de trabalho. E, neste sentido, "é possível conotar a precariedade com as relações contratuais não permanentes, associadas a um nível reduzido (ou mesmo nulo) de proteção social" (CASACA, 2005, p. 15). 
Para a autora, o trabalho precário não se esgota na fragilidade jurídica, há muitas outras variáveis envolvidas e, neste sentido, a precariedade objetiva pode ser estendida, de acordo com Casaca (2005):

[...] à ocupação de postos de trabalho pouco ou nada qualificados, a funções de pobre conteúdo e pouco valorizadas no contexto empresarial/organizacional, a condições penosas de trabalho que coloquem em risco a saúde física e psicológica dos trabalhadores, a fracas ou nulas oportunidades de qualificação, progressão e desenvolvimento profissional, a um baixo nível de remuneração, e à inadequação da função exercida em relação às qualificações obtidas (situações de sobrequalificação) (CASACA, 2005, p. 16).

Além da precariedade objetiva, o trabalho precário também comporta outra dimensão. De acordo com Casaca (2005):

[...] para que possamos rotular uma relação de trabalho de precária, é importante integrar a dimensão subjetiva - o que passa, designadamente, por tentar apreender a (in)voluntariedade que subjaz a essa relação, a percepção subjetiva da mesma (insegurança subjetiva ou incerteza); o grau de (in)satisfação com as condições de trabalho em geral (incluindo, obviamente, com o tipo de contrato) e as próprias motivações e recompensas intrínsecas decorrentes da situação de trabalho (CASACA, 2005, p. 16).

Assim, as variáveis analisadas nos permite analisar o trabalho do professor temporário (PSS) à luz da precariedade objetiva (em termos de minimização de direitos relativos à carreira e a questões salariais) e, também, sob a perspectiva da precariedade subjetiva (a percepção subjectiva da mesma, que ocasiona insegurança subjetiva ou incerteza; o grau de (in)satisfação com as condições de trabalho em geral, e as próprias motivações e recompensas intrínsecas decorrentes da situação de trabalho).

A análise das diferentes variáveis revela, ainda, que os professores temporários são privados de participar do projeto político-pedagógico da escola, cujas atividades (obrigatórias em cada escola) se realizam anteriormente ao início do ano letivo, antes das contratações temporárias, o que faz com que estes, muitas vezes, não se sintam pertencentes à instituição onde lecionam pois não participaram do planejamento do ano letivo e estão ali, muitas vezes, tão somente, para cumprir ordens - enquanto o contrato durar - e a se adaptarem às regras estabelecidas. Tal situação acaba por criar uma hierarquia entre os docentes, uma relação de poder que permite fazer uma analogia com a comunidade fictícia de Winston Parva, analisada por Elias e Scotson (2000), entre os que estão há mais tempo na instituição - os estabelecidos (efetivos) - e os novatos - outsiders (temporários). 
Assim, ao aprofundarmos a análise a respeito destes processos de remoção, percebemos que há uma grande quantidade de horas-aula disponíveis em colégios das regiões periféricas - regiões que carecem de melhores condições de segurança, infraestrutura e mobilidade urbana - e um movimento contínuo de professores efetivos que buscam remoção para colégios das regiões centrais. Estas horas-aula disponíveis acabam sendo preenchidas por professores temporários, sendo, na maioria das vezes, sua única opção.

Ao analisar uma amostra de trinta colégios das três maiores cidades do estado - Curitiba, Londrina e Maringá - cada uma delas com dez colégios, estando cinco deles localizados em bairros centrais e cinco em bairros periféricos das respectivas cidades, percebemos que as instituições localizadas em regiões periféricas tendem a contar com um maior número de profissionais com contrato temporário.

De acordo com Ayed (2012), que analisou em sua pesquisa as desigualdades sócio-espaciais da educação na França, os estabelecimentos situados nos territórios vulneráveis estão isolados no plano institucional e, além disso:

[...] concentram mais docentes novos, que sofrem um turn-over importante, o que angustia os profissionais e provoca tensões nas equipes educativas, sem falar do sentimento de abandono (AYED, 2012, p. 795-796).

Ou seja, a amostra analisada apresentou resultados similares às demais pesquisas ${ }^{3}$ que evidenciam que a localização da escola em regiões mais vulneráveis afeta a qualidade do ensino, havendo um efeito de território sobre estas escolas.

Estas situações elencadas nos permitem afirmar que o professor temporário (PSS), além da precariedade objetiva também se enquadra na dimensão subjetiva do trabalho precário, o que acaba gerando um "mal-estar docente".

A disparidade relativa à quantidade de horas-aula disponíveis nos colégios localizados em bairros centrais e periféricos, assim como a relativa à quantidade de professores temporários (PSS), sugerem que a política educacional do estado, independente do governo analisado, dado o elevado

\footnotetext{
${ }^{3}$ Nos referimos, principalmente, às pesquisas "Educação em territórios de alta vulnerabilidade social na metrópole", realizada por Érnica e Batista (2011) e "Les inégalités socio-spatiales d'accès aux savoirs: une perspective de renouvellement de la sociologie des inégalités scolaires?" (As desigualdades socioespaciais de acesso aos saberes: uma perspectiva de renovação da sociologia das desigualdades escolares?) do sociólogo e professor da universidade de Limoges (França), Choukri Ben Ayed, cujos resultados principais foram apresentados em artigo da revista Educação e Sociedade, volume 33, (2012), o qual analisa o impacto das transformações pelas quais passou o país nas disparidades territoriais de educação e relaciona-se às lógicas de fragmentação escolar e ao aumento dos processos segregadores evidenciadas por um conjunto de pesquisas realizadas anteriormente.
} 
número de professores temporários nos dois governos, não tem levado em conta a relação existente entre valorização do trabalho docente e qualidade de ensino. Nos termos de Vieira (2009):

[...] a constante substituição de professores (lembramos que os contratos em geral são de um ano, podendo ser renovados por igual período) evidencia a corrosão do significado (social) do trabalho do professor (VIEIRA et al., 2009, p.3).

Além disso, a precariedade objetiva que se buscou analisar, decorrente da instabilidade funcional em que se encontra o professor temporário, também afeta a qualidade do ensino, uma vez que os mesmos, pelo fato de não possuírem vínculo efetivo com a escola em que lecionam, não tem como participar do projeto político-pedagógico da escola (cujas atividades se realizam anteriormente ao início do ano letivo - antes das contratações temporárias - e são obrigatórias em cada escola).

Assim sendo, a política educacional adotada nos dois governos analisados na presente tese, em relação à contratação de professores temporários, tende a manter as fortes desigualdades que marcam os territórios vulneráveis, o que evidencia, também, a necessidade de uma política educacional específica para essas regiões. A constatação do elevado número de professores temporários (PSS) nos colégios pesquisados evidencia a necessidade de estudos mais aprofundados sobre a realidade educacional destes territórios e sugerem a necessidade de políticas públicas que possam interferir no sentido de compensar estas desigualdades.

\section{REFERÊNCIAS}

AYED, Choukri Ben. As desigualdades socioespaciais de acesso aos saberes: Uma perspectiva de renovação da Sociologia das Desigualdades Escolares? Educ. Soc., Campinas, v. 33, n. 120, p. 783803, jul.-set. 2012.

CASACA, Sara Falcão. Flexibilidade, Trabalho e Emprego - Ensaio de Conceptualização, Working Paper, SOCIUS nº 10/2005, ISEG-UTL. 2005.

ELIAS, Norbert \& SCOTSON, J. L. Os estabelecidos e os "outsiders": sociologia das relações de poder a partir de uma pequena comunidade. Rio de Janeiro: Jorge Zahar Ed. 2000. 
FREY, Klaus. Políticas públicas: um debate conceitual e reflexões referentes à prática da análise de políticas públicas no Brasil. In: Planejamento e Políticas Públicas, Brasília, n.21, jun. 2000, p. 211259.

MARQUES, E. Redes sociais e poder no Estado brasileiro: aprendizados a partir de políticas urbanas".Revista Brasileira de Ciências Sociais, 21 (60). 2006.

MAY, Tim. Pesquisa social: questões métodos e processos. Porto Alegre: Artmed, 2004.

VIEIRA, Renata de Almeida; SOUZA, Fatima Cristina Lucas de; MACIEL, Lizete Shizue Bomura. Repercussões da Acumulação Flexível no Campo Educacional: A Docência em foco. 2009. 